\title{
Knowledge Ecological Trees in Factor Space ${ }^{\dagger}$
}

\section{Haitao Liu * and Peizhuang Wang}

Liaoning Technical University, 47 Zhonghua Rd, Xihe Qu, Fuxin Shi 123000, China; peizhuangw@126.com

* Correspondence: haitao641@163.com

+ Presented at the IS4SI 2017 Summit DIGITALISATION FOR A SUSTAINABLE SOCIETY, Gothenburg, Sweden, 12-16 June 2017.

Published: 9 June 2017

The law of information transformation reveals the essential of cognition, to fasten the process of information transformation for cognition body, we present the knowledge ecological tree analysis and algorithm in the paper based on factor space theory, which provides a plate of mathematical description for information ecosystem.

(C) 2017 by the authors. Licensee MDPI, Basel, Switzerland. This article is an open access article distributed under the terms and conditions of the Creative Commons Attribution (CC BY) license (http://creativecommons.org/licenses/by/4.0/). 